\title{
Assessing the Effectiveness of the Redesigned Mathematics Program on Graduation and Retention Rates of Underprepared Students
}

\author{
Nancy J. McCormick \\ Mathematical Sciences Department, Middle Tennessee State University \\ P.O. Box 34, Murfreesboro, TN 37132 \\ E-mail: nancy.mccormick@mtsu.edu
}

Marva S. Lucas

University Studies Department, Middle Tennessee State University

P.O. Box 16, Murfreesboro, TN 37132

E-mail:marva.lucas@mtsu.edu

Received: July 3, 2012

Accepted: July 26, 2013

Published: August 1, 2013

doi:10.5296/jse.v3i3.3953

URL: http://dx.doi.org/10.5296/jse.v3i3.3953

\begin{abstract}
Faced with directives from the Tennessee Board of Regents (TBR), which preceded more stringent directives noted in the Complete College Act enacted in 2010, Middle Tennessee State University (MTSU) was required to eliminate the Developmental Studies program in 2006. These instructions from higher levels focused on increasing the educational attainment of Tennessee's citizens, while recognizing the decreased availability of state funding for higher education. The dictates also indicated that funding granted to higher education institutions should go beyond student enrollment to considering the numbers who are retained and graduate. On a local university level, the reality was many students satisfy overall admission criteria, but are underprepared in certain academic areas as denoted by American College Testing sub-scores. Faculty members were faced with complying with these directives while also being committed to meeting the needs of students who were admitted. MTSU was the first TBR school to implement a comprehensive redesigned program for underprepared students. Developmental mathematics courses were eliminated and prescribed
\end{abstract}




\section{Macrothink}

Journal of Studies in Education

ISSN 2162-6952 2013, Vol. 3, No. 3

sections, referred to as K-sections, of general education mathematics courses were developed. This article reports the results of an assessment of the redesigned program at MTSU on graduation and retention rates.

Keywords: Retention, Graduation rates, Underprepared postsecondary mathematics students, Redesigned mathematics programs, Program assessment for at-risk students 


\section{Introduction}

Higher education in the United States finds itself at the intersection of two crossroads: 1) the demand for college graduates and higher-skilled workers in a global economy, and 2) the increasing number of students who enter postsecondary education academically underprepared (AMATYC, 1995). Colleges and universities across the nation are being obliged to meet the needs of all incoming students (McCabe, 2000; Potts, Chatis, \& Lyttle, 2005). The Organization for Economic Cooperation and Development reported that the United States ranks tenth in the percentage of adults who have earned college degrees. In response to this sobering revelation, many initiatives have been created and implemented to increase college completion rates. President Obama, in a 2009 address to Congress, urged the U.S. to have the highest proportion of college graduates in the world by 2020 (Nelson, 2010). Responding to the goal outlined by the President, Complete College America (CCA), a Washington-based national non-profit organization, developed a single mission to work with states "to significantly increase the number of Americans with quality career certificates or college degrees to close the attainment gaps for underrepresented populations" (Complete College America, 2011a, para. 1). Pledging to continue to lend financial support to efforts intended to increase student success in higher education, the Lumina Foundation for Education, along with several other noteworthy groups, joined the alliance. Jamie P. Merisotis, Lumina Foundation president, captured the sentiment of many when he remarked, "we all acknowledge that the objective of access to higher education is not just entry, it is completion” (Nelson, 2010). Lau (2003) encouraged the higher learning academic community to focus on finding effective measures to increase retention and persistence to graduation. Admission status (Laden, Matranga, \& Peltier, 1999) and academic preparation (Cambiano, Denny, \& De Vore, 2000) are some of the factors that have been studied to gauge their influence on student retention. A study by Fike \& Fike (2008) found successful completion of developmental courses to be a significant predictor of student persistence.

The public four-year institutions in the Tennessee Board of Regents (TBR) system had an overall 41.5\% graduation rate within six years (Complete College America, 2011b). Middle Tennessee State University (MTSU), one of the four-year universities in the TBR system, graduated approximately 45\% in six years (Ferrier, 2013 \& Complete College America, 2011b). As a measure to increase the number of students who persist to complete institutional credentials, the Complete College Tennessee Act (CCTA), enacted in January 2010, outlined comprehensive reforms for public higher education in Tennessee. These reforms focused on increasing the educational attainment for citizens of the state, while recognizing the decreased availability of state funding for higher education. Directives indicated that funding granted to higher education institutions should go beyond the number of students who are enrolled to looking at the numbers who are retained and graduate. With the increased cost of education and the reduced funding at most public institutions, it is noteworthy that "studies indicate that colleges with high freshman retention rates tend to have a higher percentage of students graduating within four years," (Lau, 2003, p. 126); thereby, saving the expense associated with five or more years that many students require to graduate. 
The CCTA (2010) also required the elimination of developmental studies programs at all of its four-year public higher education institutions. However, Waycaster (2001) found a positive correlation between developmental mathematics and student retention, possibly due to extra support services and smaller class sizes. Nationally, attention to remedial education has become more prominent as the focus on college degree attainment has intensified. In fact, some suggest that remedial education can be counterproductive. The sentiment is that what was intended to help resulted in hindering the progression to completion. The sequence of courses for these purposes taken before enrolling in college-level courses provided several exit points prior to degree completion (Education Commission of the States, 2012). Others avidly acclaim the benefits of remediation. Robert McCabe, a senior fellow with the League for Innovation in the Community College, stated in an interview with Patrick Callan (2000), president of the National Center for Public Policy and Higher Education, that remediation is the most productive education program available in that it uses about one percent of the budget to salvage the lives of a half-million, thus enabling them to become positive and productive individuals in society.

At MTSU, many students satisfy overall admission criteria, but are underprepared in certain academic areas as denoted by American College Testing (ACT) sub-scores. Faculty members are faced with complying with the provisions of the CCTA while also meeting the needs of students who are admitted. According to Tinto (2012), higher education institutions must recognize the obligation to assist admitted students in their retention and progress to graduation. Implementing strategies outlined in an earlier directive, Setting New Directions: Tennessee Board of Regents (TBR) 2005-2010 Strategic Plan, MTSU was the first university in the TBR system to implement a comprehensive redesigned program for addressing the academic needs of underprepared students.

\section{Description of the New Design}

In the new design, former reading, writing, and mathematics developmental courses were eliminated. Following a model of "partial mainstreaming," the newly designed courses were housed in the respective departments but were separately coordinated (Perin, 2005). Faculty members in the former developmental program were assigned to provide instruction in the revised course structure. To meet the needs of students underprepared in mathematics, prescribed sections, designated as $\mathrm{K}$ sections, were developed for three of the general education mathematics courses: 1) liberal arts mathematics (MATH 1010), 2) college algebra (MATH 1710), and 3) applied statistics (MATH 1530). Curricula of the K-sections included the same objectives and learning outcomes as non-K sections. Likewise, students successfully completing the K-sections fulfilled three credit hours of general education mathematics requirements. Course descriptions for the prescribed sections replicate the traditional sections with the addition of supplementary algebraic content (MTSU Catalog, Undergraduate, 2013). The descriptions are as follows:

A. MATH 1010K (Mathematics for General Studies) 
This is a liberal arts mathematics course covering a variety of mathematical topics. Content includes logic, sets, algebraic reasoning, probability, statistics, and consumer mathematics. Supplementary content provides a review and enhancement of foundational algebraic topics.

\section{B. MATH 1710K (College Algebra)}

Content includes functions - linear, quadratic, exponential, and logarithmic; analysis of graphs; linear systems; inequalities; counting principles; and probability. Supplementary content provides a review and enhancement of foundational algebraic topics.

\section{MATH 1530K (Applied Statistics)}

Content includes descriptive statistics, probability, and topics of statistical inference. Supplementary content provides a review and enhancement of foundational algebraic topics.

The revised structure allowed all MTSU students to enter directly into college-credit mathematics classes. This change agreed with the National Council of State Legislatures (2011), which encouraged higher education institutions to innovatively consider enrolling students directly in college-level courses while providing additional academic support as needed in an effort to improve remedial education. Students enrolling directly into college-credit courses tend to form more positive attitudes and to devote more time and effort to their coursework (Crawford, 1993; Maxwell, 1997). The new structure, which embeds additional foundational concepts, also conforms to CCA's recommendation to address methods that enable full-time and part-time students to have "new, shorter, and faster pathways to degree and certificates of value” (Complete College America, 2011c, p. 9).

The TBR currently defines students with ACT mathematics scores below 19 to be underprepared for college mathematics. K-sections were designed to address student deficiencies in mathematics while also demanding the higher level skills for successful completion of general education credits. The redesign of the mathematics program at MTSU has been supported by recent studies indicating that the reorganization of curricula and instruction is a popular strategy for accelerating and improving outcomes for underprepared students (Edgecombe, 2011). While challenging the students to work at a more advanced level, the curriculum of the K-sections was specifically developed to support the academic needs of underprepared students. To accomplish these objectives, the curriculum for each course incorporated a vital technology component and required additional contact hours to provide prerequisite content to support students' progress in the course and to enable their successful completion. Each course in the redesign required five contact hours in the classroom. Similar to the former design, class enrollment was capped at 25, and all students placed in the courses had ACT Mathematics sub-scores less than 19. Courses in the new design incorporated a technology component that included online homework, test reviews, practice tests, video lectures, etc. to supplement in-class instruction (Lucas \& McCormick, 2007). The newly developed program for underprepared mathematics students, with the exception of the MATH 1530K course, was initially implemented in fall 2006, and has been used in all subsequent years. MATH 1530K was first offered in fall 2011 and is not included for purposes of this study. The redesign at MTSU, mainstreaming all students into 
college-credit mathematics, has gained state-wide recognition and attention in both national and international venues.

The redesigned mathematics program serves the needs of a substantial student population at MTSU. In general, MTSU serves an undergraduate population of approximately 22,000 students. The numbers of students enrolled in prescribed K-sections of general education mathematics courses beginning with the 2006-2007 academic year are given below:

Table 1. Course Enrollment

\begin{tabular}{|cc|}
\hline Academic Year & MATH 1010K and MATH 1710K \\
\hline $2006-2007$ & 1840 \\
\hline $2007-2008$ & 1799 \\
\hline $2008-2009$ & 2108 \\
\hline $2009-2010$ & 2220 \\
\hline $2010-2011$ & 2347 \\
\hline $2011-2012$ & 1823 \\
\hline
\end{tabular}

\section{Purpose of the Study}

As the new design entered its seventh year in fall 2012, the purpose of this study was to assess the effect (if any) of the redesigned mathematics program on graduation and retention rates for at-risk students in mathematics. The former design for developmental education offered all developmental courses through a centralized department. Underprepared mathematics students had to successfully complete an intermediate algebra course, DSPM 0850, for institutional credit only, before proceeding to enroll in a college-credit general education mathematics course (Lucas \& McCormick, 2007). This delay in the completion of general education credits for mathematics added a minimum of one additional semester to a student's degree program. Adelman (2006) showed that $71 \%$ of students eventually complete a bachelor's degree if they have satisfied their college mathematics credits by the end of their sophomore year, compared to a $38 \%$ graduation rate for students who have not. A successful first year experience has been shown to be instrumental in improving graduation and retention rates (Kelly, 2006). With the acceleration of a student's completion of general education mathematics credits, the added technology component, the additional student contact hours, and a more advanced curriculum, the redesigned mathematics program was expected to positively impact the first year experience and learning outcomes for students underprepared in mathematics. The study reports the results of the redesigned program at MTSU on retention and graduation rates for at-risk students.

\section{Methodology}

To evaluate the effectiveness of the redesigned mathematics program, the study compared graduation and retention rates of students in the former developmental mathematics program to students in the redesigned program. Both programs included students identified by the 
TBR as underprepared in mathematics based on ACT scores. Going into the courses, the student groups had equivalent academic ability based on ACT standards. The quality of instruction was equivalent in that the same faculty provided instruction in both programs. Contact hours were increased to accommodate the more advanced curriculum, and the redesign added a prominent technology component.

For purposes of the study, graduation is defined as successful completion of a baccalaureate degree at MTSU within five or six years of initial enrollment. The study also investigated second-year retention rates for the two cohorts of students. First-year students were identified as those students enrolled in DSPM 0850 or in MATH 1710 in fall 2000; and those students enrolled in MATH 1010K, MATH 1710K, MATH 1010, or MATH 1710 in fall 2006. Second-year students were defined by continued enrollment at MTSU in fall 2001 and fall 2007, respectively. The study measured the second-year retention rates by the ratio of second-year students to first-year students as defined in the study. Data were used to make the following comparisons:

A. Graduation and retention rates for students whose initial enrollment was in MATH $1010 \mathrm{~K}$ or MATH $1710 \mathrm{~K}$ were compared to graduation and retention rates for students who under the former design were initially enrolled in DSPM 0850.

B. Graduation and retention rates for students whose initial enrollment was in MATH $1010 \mathrm{~K}$ or MATH $1710 \mathrm{~K}$ were compared to graduation and retention rates for students in traditional sections of MATH 1010 or MATH 1710 with ACT mathematics scores of 19 and 20.

C. Graduation and retention rates for students whose initial enrollment was in MATH 1010K or MATH $1710 \mathrm{~K}$ were compared to graduation and retention rates for all students in traditional sections of MATH 1010 or MATH 1710.

\section{Limitations}

A noted limitation is the research includes only the number of students graduating from MTSU. Some students may have transferred and persisted to graduation from another institution. The enrollment numbers for MATH 1010 in fall 2000 were minimal and, consequently, not used in the study. Inferences made from statistical results are applicable only to future student populations characterized by the same constraints as those students in the study.

\section{Results}

The researchers gathered the numbers of first-time, full-time freshmen entering the developmental mathematics program or enrolling directly in MATH 1710 in fall 2000. Both five- and six-year cohorts of these students were tracked through fall 2005 and fall 2006, respectively, to identify the proportion of students who completed their degrees either in the five- or six-year period. These data and a summary of percentages of students who graduated in the five- or six-year period are presented in Table 2 and Table 3. 
Table 2. Five-Year Cohorts of First-Time, Full-Time Freshmen (Fall 2000)

\begin{tabular}{|llll|}
\hline & Enrolled in Aug. 2000 & Graduated by Aug. 2005 & Graduation \% \\
\hline DSPM 0850 & 400 & 106 & 26.5 \\
\hline MATH 1710 & 494 & 229 & 46.4 \\
\hline
\end{tabular}

Table 3. Six-Year Cohorts of First-Time, Full-Time Freshmen (Fall 2000)

\begin{tabular}{|lccc|}
\hline & Enrolled in Aug. 2000 & Graduated by Aug. 2006 & Graduation \% \\
\hline DSPM 0850 & 400 & 145 & 36.3 \\
\hline MATH 1710 & 494 & 250 & 50.6 \\
\hline
\end{tabular}

A comparison between graduation rates of students in DSPM 0850 and MATH 1710 showed students with weaker mathematics backgrounds were less likely to graduate on either a fiveor six-year continuum than students placed directly into college algebra. Given that the former program necessarily added at least one semester, the difference in graduation rates for the six-year cohorts (14\%) was, as might be expected, less than the $20 \%$ difference found for the five-year cohorts. The numbers also showed an almost $10 \%$ gain in graduation rates from a five- to six-year period for students with initial enrollment in DSPM 0850 and an approximate 4\% gain for students whose initial enrollment was in MATH 1710.

In fall 2006, the new design was first implemented and entering freshmen with ACT mathematics sub-scores of 17 or 18 were placed in prescribed sections of MATH $1710 \mathrm{~K}$ and MATH 1010K. Data for five-year and six-year cohorts summarizing graduation rates in traditional sections and in $\mathrm{K}$ sections are given in Table 4 and Table 5.

Table 4. Five-Year Cohorts of First-Time, Full-Time Freshmen (Fall 2006)

\begin{tabular}{|lccc|}
\hline & Enrolled in Aug. 2006 & Graduated by Aug. 2011 & Graduation \% \\
\hline MATH 1710K & 426 & 129 & 30.3 \\
\hline MATH 1710 & 555 & 235 & 42.3 \\
\hline MATH 1010K & 123 & 31 & 25.2 \\
\hline MATH 1010 & 179 & 65 & 36.3 \\
\hline MATH 1710K \& 1010K & 549 & 160 & 29.1 \\
\hline MATH 1710 \& 1010 & 734 & 300 & 40.9 \\
\hline
\end{tabular}


Table 5. Six-Year Cohorts of First-Time, Full-Time Freshmen (Fall 2006)

\begin{tabular}{|lccl|}
\hline & Enrolled in Aug. 2006 & Graduated by Aug. 2012 & Graduation \% \\
\hline MATH 1710K & 426 & 156 & 36.6 \\
\hline MATH 1710 & 555 & 285 & 51.4 \\
\hline MATH 1010K & 123 & 39 & 31.7 \\
\hline MATH 1010 & 179 & 71 & 39.7 \\
\hline MATH 1710K \& 1010K & 549 & 195 & 35.5 \\
\hline MATH 1710 \& 1010 & 734 & 356 & 48.5 \\
\hline
\end{tabular}

To make inferences for future student populations characterized by similar constraints as those in the study, the researchers tested the data using a significance level of alpha $=.05$ to determine if a statistically significant difference in graduation rates was evidenced for the five-year and/or the six-year cohorts. A comparison between graduation rates of students in MATH $1710 \mathrm{~K}$ and MATH 1710 showed the following:

A. For the five-year cohort (Table 4), a 2-Proportion Z Test showed first-time, full-time freshmen in MATH 1710 graduated at a significantly higher rate than first-time, full-time freshmen in MATH 1710K $(\mathrm{p}<.0001)$.

B. For the six-year cohort (Table 5), a 2-Proportion $\mathrm{Z}$ Test again showed first-time, full-time freshmen in MATH 1710 graduated at a significantly higher rate $(p<.0001)$ than their counterparts in MATH 1710K.

For graduation rates of students in MATH 1010K and MATH 1010, testing evidenced the following results:

A. For the five-year cohort (Table 4), a 2-Proportion Z Test showed first-time, full-time freshmen in MATH 1010 graduated at a significantly higher rate than first-time, full-time freshmen in MATH 1010K ( $\mathrm{p}=.0208)$.

B. For the six-year cohort (Table 5), a 2-Proportion Z Test showed no significant difference in graduation rates of first-time, full-time freshmen in MATH 1010 and first-time, full-time freshmen in MATH 1010K ( $\mathrm{p}=.0790)$.

The researchers went further to compare students with ACT mathematics sub-scores 19 or 20 enrolled in MATH 1710 and in MATH 1010 to students with ACT mathematics sub-scores 17 or 18 enrolled in MATH $1710 \mathrm{~K}$ and in MATH 1010K, respectively. These comparison groups are judged by ACT scores to be more similar in beginning mathematical skills. Data are given in Table 6 and Table 7. 
Table 6. Five-Year Cohorts of First-Time, Full-Time Freshmen (Fall 2006)

\begin{tabular}{|lccc|}
\hline & Enrolled in Aug. 2006 & Graduated by Aug. 2011 & Graduation \% \\
\hline MATH 1710K & 426 & 129 & 30.1 \\
\hline $\begin{array}{l}\text { MATH 1710 } \\
\text { (ACT Math 19 or 20) }\end{array}$ & 149 & 33 & 22.1 \\
\hline MATH 1010K & 123 & 31 & 26.8 \\
\hline $\begin{array}{l}\text { MATH 1010 } \\
\text { (ACT Math 19 or 20) }\end{array}$ & 70 & 20 & 28.6 \\
\hline MATH 1710K \& 1010K & 549 & 160 & 29.1 \\
\hline $\begin{array}{l}\text { MATH 1710 \& 1010 } \\
\text { (ACT Math 19 or 20) }\end{array}$ & 219 & 53 & 24.2 \\
\hline
\end{tabular}

Table 7. Six-Year Cohorts of First-Time, Full-Time Freshmen (Fall 2006)

\begin{tabular}{|lccl|}
\hline & Enrolled in Aug. 2006 & Graduated by Aug. 2012 & Graduation \% \\
\hline MATH 1710K & 426 & 156 & 36.6 \\
\hline $\begin{array}{l}\text { MATH 1710 } \\
\text { (ACT Math 19 or 20) }\end{array}$ & 149 & 54 & 36.2 \\
\hline MATH 1010K & 123 & 39 & 31.7 \\
\hline $\begin{array}{l}\text { MATH 1010 } \\
\text { (ACT Math 19 or 20) }\end{array}$ & 70 & 27 & 38.6 \\
\hline MATH 1710K \& 1010K & 549 & 195 & 35.5 \\
\hline $\begin{array}{l}\text { MATH 1710 \& 1010 } \\
\text { (ACT Math 19 or 20) }\end{array}$ & 219 & 81 & 37.0 \\
\hline
\end{tabular}

It was supportive of the new design that graduation rates for students in MATH 1710K were observed to be 8\% higher than MATH 1710 (ACT mathematics sub-scores 19 or 20) for the five-year cohorts. At a significance level of .05 and using a 2-Proportion Z Test, a comparison between graduation rates of students in MATH 1710K and MATH 1710 (ACT mathematics sub-scores 19 or 20) showed the following:

A. For the five-year cohort (Table 6), first-time, full-time freshmen in MATH $1710 \mathrm{~K}$ graduated at a significantly higher rate than first-time, full-time freshmen in MATH 1710 with ACT mathematics sub-scores 19 or $20(\mathrm{p}=.0287)$.

B. For the six-year cohort (Table 7), testing showed no significant difference in graduation rates of first-time, full-time freshmen in MATH $1710 \mathrm{~K}$ and first-time, full-time freshmen in MATH 1710 with ACT mathematics sub-scores 19 or $20(p=.4671)$.

A comparison between graduation rates in MATH 1010K and MATH 1010 (ACT mathematics sub-scores 19 or 20 ) gave the following results: 
A. For the five-year cohort (Table 6), a 2-Proportion Z Test showed no significant difference in graduation rates of first-time, full-time freshmen in MATH $1010 \mathrm{~K}$ and first-time, full-time freshmen in MATH 1010 with ACT mathematics sub-scores 19 or 20 (p $=.3972)$.

B. For the six-year cohort (Table 7), a 2-Proportion Z Test again showed no significant difference in graduation rates of first-time, full-time freshmen in MATH $1010 \mathrm{~K}$ and first-time, full-time freshmen in MATH 1010 with ACT mathematics sub-scores 19 or 20 (p $=.1669)$.

These results were also encouraging in that for both five-year and six-year cohorts, there was no statistically significant difference in the graduation rates of students in K-sections of MATH 1010 and students with ACT mathematics sub-scores 19 or 20 in traditional sections of MATH 1010.

When comparing the combined results for students with ACT mathematics sub-scores 19 or 20 enrolled in MATH 1710 and MATH 1010 traditional sections to K sections for both fiveand six-year cohorts, as noted in Tables 6 and 7, the graduation rate for $\mathrm{K}$ sections in the five-year cohort was higher, though not significantly higher $(\mathrm{p}=.0836)$. Comparing the results for the six-year cohort showed no significant difference between the graduation rates $(\mathrm{p}=.3510)$. Additional academic assistance in K-sections allowed students with a lower assessed skill level to accelerate to degree completion within the five-year period more quickly than those students with ACT mathematics sub-scores 19 or 20.

The study analyzed retention data gathered from both fall 2000 and fall 2006 cohorts. One-year retention rates were determined by finding the numbers from the two cohorts who had continued enrollment in fall 2001 and fall 2007, respectively. The study examined whether the new design promoted higher student retention among students who were initially underprepared for college mathematics. Table 8 and Table 9 provide one-year retention rates for cohorts of MTSU students in DSPM 0850 and in traditional and prescribed sections of MATH 1710 and MATH 1010.

Table 8. Retention Rates for Former Mathematics Design

\begin{tabular}{|lccl|}
\hline & Enrollment Fall 2000 & Enrollment Fall 2001 & Retention \% \\
\hline DSPM 0850 & 400 & 263 & 65.8 \\
\hline MATH 1710 & 494 & 371 & 75.1 \\
\hline
\end{tabular}


Table 9. Retention Rates for New Mathematics Design

\begin{tabular}{|lccl|}
\hline & Enrollment Fall 2006 & Enrollment Fall 2007 & Retention \% \\
\hline MATH 1710K & 426 & 286 & 67.1 \\
\hline MATH 1710 & 555 & 395 & 71.2 \\
\hline MATH 1010K & 123 & 76 & 61.8 \\
\hline MATH 1010 & 179 & 117 & 65.4 \\
\hline
\end{tabular}

From the former design, a comparison showed retention rates for students in MATH 1710 to be approximately 10\% higher than the retention rates for DSPM 0850. Comparing retention rates of students in MATH 1710 to MATH $1710 \mathrm{~K}$ indicated no statistically significant difference $(\mathrm{p}=.0870)$. Likewise, comparing the retention rates of students in MATH 1010 to MATH 1010K showed no significant difference $(p=.2626)$.

\section{Conclusion}

Graduation and retention rates for five- and six-year cohorts of students whose initial enrollment was in MATH $1010 \mathrm{~K}$ or MATH $1710 \mathrm{~K}$ were compared to graduation and retention rates for a five- and six-year cohorts of students who under the former design were initially enrolled in DSPM 0850, as follows.

A. The five-year graduation rate for students in MATH $1010 \mathrm{~K}$ or MATH $1710 \mathrm{~K}$ was $160 / 549$ or $29.1 \%$. The graduation rate for students enrolled in DSPM 0850 was $106 / 400$ or $26.5 \%$. Though the graduation rate was found to be higher for the new design, it was not significantly higher $(\mathrm{p}=.1853)$.

B. The six-year graduation rate for students in MATH $1010 \mathrm{~K}$ or MATH $1710 \mathrm{~K}$ was $195 / 549$ or $35.5 \%$. The graduation rate for students enrolled in DSPM 0850 was $145 / 400$ or $36.3 \%$. There was no significant difference in the graduation rates of six-year cohorts ( $\mathrm{p}$ $=.4083)$.

C. The one-year retention rate for students in MATH $1010 \mathrm{~K}$ or MATH $1710 \mathrm{~K}$ was $362 / 549$ or $65.9 \%$. The one-year retention rate for students in DSPM 0850 was $263 / 400$ or $65.8 \%$. Again, this was not a significant difference $(\mathrm{p}=.4759)$.

Although there was no significant difference in graduation and retention rates between the former and new designs, the new design benefits students by satisfying general education mathematics credits with MATH 1710K, MATH 1010K, or MATH 1530K. Completing general education mathematics requirements in the initial semester of enrollment eliminates the time and tuition expense (Lucas \& McCormick, 2010) associated with DSPM 0850, which had afforded institutional credit only. The percent change in graduation rates from five years to six years was $36.8 \%$ for the former design and $21.9 \%$ for the new design. The smaller percent change for the new design indicates that students are progressing more rapidly to graduation (See Tables 2, 3, 4, and 5). 


\section{MlMacrothink}

Journal of Studies in Education

ISSN 2162-6952

2013, Vol. 3, No. 3

The redesigned mathematics program also follows recommendations for faster pathways to degree attainment as outlined by Complete College America (2011c), such as diverting students from traditional remedial programs and mainstreaming students into college-level courses in which remediation is embedded. The college-level courses in the redesigned program have intensified instruction requiring students to work at a more advanced level while minimizing the time to degree completion.

Additionally, the results indicate that the five-year cohort of students placed by ACT mathematics sub-scores 17 or 18 into MATH $1710 \mathrm{~K}$ had higher graduation rates than the students who had ACT mathematics sub-scores 19 or 20 and, accordingly, placed into MATH 1710. However, for students with 19 or 20 ACT mathematics sub-scores, comparisons for six-year cohorts in MATH 1710K and MATH 1710 and six-year cohorts in MATH 1010K and MATH 1010 showed no significant difference in graduation rates. This seems to indicate that the new design is proving effective in that the same or better graduation rates are evidenced for students with ACT mathematics sub-scores 17 or 18 as for students with ACT mathematics sub-scores 19 or 20.

\section{Implications}

Students with ACT mathematics sub-scores 19 or 20 might be better served through the additional academic assistance provided by the K-courses as opposed to initial enrollment in regular sections of MATH 1710 and MATH 1010. Further research making comparisons limited only to students with ACT mathematics sub-score 19 enrolled in non-K sections and students in the prescribed sections of the respective courses may be more informative as to the effectiveness of the program. Additional research at MTSU as to the effect of the current redesign of mathematics employing more recent groups of cohorts would be helpful to identify successful components and strategies of the program. More far-reaching research is warranted to explore the effectiveness of redesigned mathematics programs throughout the TBR system, in general. The goal of all programs system wide is to increase student success in completing academic requirements for graduation in a more efficient and timely manner.

\section{Acknowledgement}

The research for this study was funded through a Middle Tennessee State University Instructional Evaluation and Development Grant.

\section{References}

Adelman, C. (2006). The Tool Box Revisited. Office of Educational Research and Improvement, US Department of Education.

American Mathematical Association of Two-Year Colleges (AMATYC). Cohen, D. (Ed). (1995). Crossroads in Mathematics: Standards for Introductory College Mathematics Before Calculus. Memphis, TN: American Mathematical Association of Two-Year Colleges.

Callan, P. M. (2000) An interview: Robert McCabe. National Crosstalk. Retrieved from http://www.highereducation.org/crosstalk/ct1000/interview1000.shtml 
Cambiano, R. L., Denny, G. S., \& De Vore, J. B. (2000). College student retention at a midwestern university: a six-year study. Journal of College Admission, 166, 22-29.

Complete College America. (2011a). About us. Retrieved from http://www.completecollege.org/about/

Complete College America. (2011b). Tennessee 2011. Retrieved from http://www.completecollege.org/docs/Tennessee.pdf

Complete College America. (2011c). Time is the enemy. Retrieved from http://www.completecollege.org/docs/Time_Is_the_Enemy.pdf

Complete college Tennessee act. (2010). Retrieved from http://www.tn.gov/thec/complete_college_tn/ccta_files/ccta/Pub\%20Chap\%203\%20-\%201st \%20Ex\%20Sess.PDF

Crawford, J. J. (1993). Recession and the role of developmental education: An interview with John N. Gardner. Journal of Developmental Education, 17(1), 22-24, 26, 41.

Edgecombe, N. (2011). Accelerating the academic achievement of students referred to developmental education. Community College Research Center Evidence Series, CCRC Working Paper No. 30.

Education Commission of the States (2012). Core principles for transforming remedial education: A joint statement. Retrieved from http://www.ecs.org/docs/STATEMENTCorePrinciples.pdf

Ferrier, D. (2013, May 9). Graduation rates show taxing issue at TN public colleges. Retrieved from http://wsmv.membercenter.worldnow.com/story/22082059/graduation-rates-show-taxing-issu e-at-tn-public-colleges

Fike, D. S., \& Fike, R. (2008). Predictors of first-year student retention in the community college. Community College Review. http://dx.doi.org/10.1177/0091552108320222

Kelly, J. M. (2006). The first year experience: Strategies for improvement. Retrieved from http://www.newfoundations.com/OrgTheory/Kelly721Sp06.html

Laden, R., Matranga, R., \& Peltier, G. (1999). Persistence of special admissions students at a small university. Education, 120(1), 76-81.

Lau, L. K. (2003). Institutional factors affecting student retention. Education, 124(1), 126-136.

Lucas, M., \& McCormick, N. (2010). Assessing the cost of redesigning developmental education. NADE Digest, 5(1), 21-29.

Lucas, M. S., \& McCormick, N. J. (2007). Redesigning mathematics curriculum for underprepared college students. The Journal of Effective Teaching, 7(2), 36-50. 


\section{Macrothink}

Journal of Studies in Education

ISSN 2162-6952

2013, Vol. 3, No. 3

Maxwell, M. (1997). What are the functions of a college learning assistance center? Retrieved from http://www.eric.ed.gov/PDFS/ED413031.pdf

McCabe, R. (2000). Underprepared students. Measuring Up 2000: The State-by-State Report Card for Higher Education. Retrieved from http://www.eric.ed.gov/PDFS/ED450633.pdf

MTSU Catalog, Undergraduate. (2013). Retrieved from http://catalog.mtsu.edu/content.php?catoid=10\&navoid=407\#acalog_template_course_filter

National Council of State Legislatures. (2011). Improving college completion: Reforming remedial education. Retrieved from http://www.ncsl.org/documents/educ/ReformingRemedialEd.pdf

Nelson, L. (2010, March 2). 17 states pledge to increase graduation rates, joining a new national effort. The Chronicle of Higher Education. Retrieved from http://chronicle.com/article/17-States-Pledge-to-Increase/64443/

Potts, K., Chatis, C., \& Lyttle, E. (2005). Teaching kids math: Is Tennessee doing enough? Retrieved from http://comptroller.tn.gov/repository/RE/math_proficiency.pdf

Tennessee Board of Regents (2005). Setting new directions: Tennessee Board of Regents 2005-2010 strategic plan. Retrieved from http://www.tbr.edu/offices/academicaffairs.aspx?id=3850

Tinto, V. (2012). Completing college: rethinking institutional action. Chicago, IL: University of Chicago Press. http://dx.doi.org/10.7208/chicago/9780226804545.001.0001

Waycaster, P. (2001). Factors impacting success in community college developmental mathematics courses and subsequent courses. Community College Journal of Research and Practice, 25, 403-416. http://dx.doi.org/10.1080/106689201750192256 